\title{
Private-public strategies for sustainable regional development (3rd Greening of Industry Network Conference in Mexico City)
}

Article citation: María-Laura Franco-García, Juan-Luis Sherwell and Aard Groen, (2013) "Private-public strategies for sustainable regional development (3rd Greening of Industry Network Conference in Mexico City)", Management Research Review, Vol. 36 Iss: 12, pp. -

\section{Article Type: Guest editorial From: Management Research Review, Volume 36, Issue 12}

Keywords: Sustainable development

\begin{abstract}
About the Guest Editors
María-Laura Franco-García is a Senior Researcher on environmental voluntary policy strategies, sustainable co-created products by BoP's and social responsibility of SMEs at CSTM-Twente Centre of Studies in Technology and Sustainable Development, University of Twente, The Netherlands. Former Director of Academic Department and Master's Programme of Sustainable Development Sciences at the "Instituto Tecnológico y de Estudios Superiores de Monterrey", Mexico. Post-doctorate in Hokkaido University, Japan; PhD and Master's degrees on environmental science obtained at the "Institute Nationale des Sciences Appliquées" in Lyon, France. Environmental Engineer by training at the Universidad Autonoma Metropolitana in Mexico City.

Juan-Luis Sherwell is a Director of EGADE Business School, Mexico State campus at the "Instituto Tecnológico y de Estudios Superiores de Monterrey". Director of Executive MBA and Director of MBA Programme in Santa Fe campus. Sherwell obtained his PhD and Master's degrees on economy at Texas Tech University, USA and studied economy at the "Universidad de las Américas", Puebla, Mexico. Sherwell is actively interviewed as opinion-leader by Mexican media for his contributions to different scientific and professional journals.
\end{abstract}

Aard Groen is a Professor of innovative entrepreneurship and scientific Director of The Netherlands Institute for Knowledge Intensive Entrepreneurship (NIKOS) at the University of Twente, The Netherlands. His publications are positioned in the fields of entrepreneurship, marketing, university-industry interaction and innovation and technology dynamics. Master's degree on public administration at the University of Twente, and PhD on business administration at the University of Groningen, The Netherlands.

\section{Introduction}

In the editorial article of the special issue of Volume 33 of this journal, Margaret Gollagher and Joseph Sarkis introduced the "Greening of Industry Network" (GIN) accordingly to its definition and mission published in the GIN web site (www.greeningofindustry.org). Being an international network of professionals from different societal sectors dedicated to build a sustainable future, GIN has been considered, since its first conference in 1991, as a platform "to develop knowledge and transformation to accelerate progress toward a sustainable society". With a total of 34 events, including large international conferences and local workshops held in different countries and continents, GIN has a long and thoughtful history for the exchange of knowledge and innovative perspectives on greening and sustainability. The large diversity of its hundreds of participants around the world has stirred the ongoing network re-organisation, and supported the growth of the GIN coordination team from three to nine coordinators who are based in NorthAmerica, Europe and Asia.

As part of the GIN event's outcomes, the GIN coordinators promote the selection of suitable papers to be included in scientific publications, i.e. conference edited books or journal special issues. To build on this tradition and history, the theme of this special issue corresponds to that of the 3rd Greening of Industry Network (GIN) Conference in Mexico City, held on April 18-20, 2012. This conference was co-organised by GIN, the University of Twente and the "Instituto Tecnológico y de Estudios Superiores de Monterrey". Hence, this special issue focuses on "Private-public strategies for sustainable regional development" to 
facilitate the transformation to sustainable societies on regional geographic scales. The main research questions driving the conference were as follows: "Why strategies for sustainable regional development?" and, "Can collaborative strategies by multi-stakeholders facilitate the conditions towards sustainable regional development models?"

Business, commerce and industry operate in increasingly global settings. Sustainable development is also closely connected to global systemic changes, and regional settings demands additional attention for efficient operation of private-public strategies implementation. Furthermore, due to the interconnection between sustainable production and consumption patterns, collaboration among all the parties involved is currently seen as an important success factor. Consequently, business, governments, citizens and NGOs need to meet at the regional level and interact. During the 3rd GIN Conference in Mexico City, stakeholders from those sectors participated by sharing their experiences and visions about "sustainable regional development".

The Call for Papers of the 3rd GIN Conference in Mexico City included some of the most relevant topics that organisers chose to illustrate as some of the good practices/strategies related to the theme of "Privatepublic strategies for sustainable regional development". These included:

- $\quad$ sustainable industrial parks;

- new venture platforms for creation of cleantechnological businesses;

- $\quad$ private sector strategy: case studies showing best practices;

- $\quad$ public-private partnerships to promote sustainability;

- triple helix collaboration: institutes of higher education leading capacity adaptation towards sustainable innovation;

- multi stakeholder participation for development: multifunctionality of landscapes - combining agricultural, industrial, tourism and city developments;

- industrial and non-industrial supply chains;

- inter-and intra-organizational collaborations; and

- $\quad$ managing and scaling global sustainability efforts into local execution.

During the closing of the conference, most participants agreed that "collaboration" among stakeholders is a key factor for implementing strategies to develop a region according to the principles of sustainability. Global demand and global systematic changes have driven business, commerce and industry operations; however, it was clearly identified that regional settings have a crucial influence on the implementation phase of the public, private or public-private strategies. Moreover, a number of papers presented showed that in practice, companies need to deal with regional conditions which are to a large extent dictated by governmental actors but more importantly, at present, those conditions can be actively transformed by other societal actors, mirroring the relevance of social and environmental performance of companies.

Equally important, leadership came across as one of the crucial characteristics of actors for creating collaborative conditions among stakeholders, such as transparency and trust.

\section{Overview of the papers}

We began the selection process with 17 papers that most strongly reflected the aim of this special issue. After further revisions, this number was reduced to seven papers. The remaining papers were submitted at minimum two peer review processes. It is entirely coincidental that the papers included in this issue are oriented to explain some theories and practices either in the European region (The Netherlands in a more specific context) or in Mexico (at national level and locally with two specific cases in Mexico State and Chiapas).

The first paper of issue is entitled "Convergence of boundary judgments and innovative regional development concepts" and is written by Hans Bressers and Cheryl de Boer. The authors focus on the conceptual framework of "sustainable regional development", stressing that it is often accompanied by the introduction and gradual implementation of innovative concepts, like, e.g. "integrated natural resources 
management" or "sustainable tourism". From a managerial perspective, in order to contribute to improved sustainable regional development the innovative concepts need to become rooted in everyday policy practice in such a way that they enable rather than hinder collective action. Enabling collective action through collaboration is posed in this paper as a managerial challenge that is partly dependent on the presence of a sufficient degree of integration in the governance system that forms a context for the action. This challenge can be studied with the help of the concept of boundary judgments. Boundary judgments are normative and cognitive perceptions of actors on the relevancy of specific actors, factors, issues, etcetera, for their domain of action (what is "fit", what is acceptable, what is needed?). The authors illustrate the impact of these boundary judgements through two empirical studies in The Netherlands.

The following paper that is elaborated by Yoram Krozer, María-Laura Franco-García and David Micallef, with the title of "Interactions management in environmental policy", addresses regulator - management interactions in environmental policy with reference to direct regulations, social regulations and market-based regulations. These interactions cause high and growing transaction costs; in The Netherlands during 19902007 they represent an increase from 17 to 21 percent of all environment protection costs. Rapid annual growth (avg. 14 percent) followed the shift from direct to social regulations in the 1990s. Instead of the shift, better interactions management could have saved nearly $€ 4$ billion a year in the EU region. In support of this, a web-based expert system was developed collaboratively in a consortium of small and medium size enterprises and expert centres from seven European countries. The system, "Environmentor", contains checklists with exemplary inputs, outputs, environmental standards and technologies for permits, a process for implementation of environmental management systems, as well as an administrative model and auction for the EU emission trading; "Environmentor" serves SME's to deal with public and private environmental policy instruments in the European region.

Jorge-Carlos Carpio-Aguilar and María-Laura Franco-García contributed the third paper of this special issue. This paper presents an analysis of the influence of "Joint environmental policy-making" (JEP) in the operation of the company Smurfit Kappa (SK) in The Netherlands, Austria and Denmark (NL\&AD). SK represents one of the main cardboard producers, which leads the European packaging market in terms of best environmental practices. The practice of recycling paper has contributed to The Netherlands being ranked 11th worldwide (CDP, 2012) while Austria and Denmark were positioned 17th and 20th, respectively. In this paper the authors address the question: To what extent have different levels of jointness and voluntariness (from JEP's model) of cardboard packaging-chain agreements between Federal (NL\&AD), governmental and business actors led to different recycling performances within the same company (SK)? Some conclusions were drawn from the literature and empirical evidences gathered from the research carried out, from which, jointness and voluntariness of the JEP's model could be associated to collaborative attitudes of actors from public and private sectors to enable the cardboard recycling cycle.

The paper entitled "Water resource co-management and sustainable regional development" by Cheryl de Boer and Hans Bressers explored the many challenges that are associated with the sustainable use and management of water at the regional level. In relation to this, a plethora of policies have been developed at many levels of government to address the water issues and can complicate the environment in which actions of local stakeholders take place. The water itself is not directly affected through these policies, but through what happens as a result of them being put into action. The Netherlands provides a particularly interesting example of innovative implementation efforts since water management has a long history and importance in the daily lives of its citizens. This article explores actions focused on planning for multifunctionality, increasing space for rivers and the connection of natural areas. These efforts are at the heart of new collaborative initiatives in the Dutch rural areas to meet European and National habitat and water quality and quantity goals.

Dennis J. Aigner and Antonio Lloret show in their paper of "Sustainability and competitiveness in Mexico" some of their most relevant findings of a research project that aimed at benchmarking the environmental sustainability practices of the top 500 Mexican companies. This was done by surveying firms with regard to various aspects of their adoption of environmental sustainability practices, including who or what prompted adoption, future adoption plans, decision-making responsibility, and internal/external challenges that requires of more active collaboration with the firms' stakeholders. The survey also explored how the adoption of environmental sustainability practices relates to the competitiveness of these firms. A total of 103 self-selected firms representing the six primary business sectors in the Mexican economy were the subject of this analysis. Aigner and Lloret's results suggest that Mexican companies are very active in the various areas of business where environmental sustainability is relevant. Not surprisingly, however, the Mexican companies are seen to be at an early stage of development along the sustainability "learning curve". The vast majority of these firms see adopting environmental sustainability practices as being profitable and think this will be even more important in the future. 
The contribution of industrial parks to regional development has been the driving force for some companies to geographically cluster together under some political programs. "Sustainable industrial parks" framed the research done by Edgardo Bastida-Ruiz, María-Laura Franco-García and Isabel Kreiner in their paper entitled: "Analysis of indicators to evaluate the industrial parks contribution to sustainable development: Mexican case". In this paper, the authors suggested a sustainability indicators framework for industrial parks in contexts where information is weakly reliable or insufficient. In order to provide a more realistic (measurable) set of sustainability indicators for the Mexican context and more specifically for Mexican industrial parks located in the central region, the authors firstly carried out an analysis of secondary information sources for matching sustainability indicators with available related data which is reported by companies along their certification processes. The main purpose of doing this was to construct the indicators framework that was explored empirically in the second phase of this research. During this phase, the authors validated such framework by means of surveys and interviews to gather the perceptions of Mexican business managers about the list of prior selected United Nations indicators (Kreiner et al., 2011), these were coupled to available certifications in Mexico. By promoting sustainability measures within industrial parks, authors equally recommended to enable collaborative conditions among actors from industries, governments, industrial park organisations, chambers of commerce and local communities.

The seventh and final paper in this special issue is written by Luz-del-Carmen Díaz-Peña, Anselmo Salvador Chavez-Capo, Miguel Angel Tinoco-Castrejón, Genoveva Rosano-Ortega and Beatriz PérezArmendariz. Authors of the entitled paper "Financial assessment of a biodiesel value chain: case study of Chiapas, Mexico" assessed the biodiesel value chain that the State of Chiapas produces and, through a financial model, determined its profitability and feasibility as a business. Even further, with the purpose to enhance stakeholders collaboration, authors expected that this paper could serve as a reference for those involved in the production and commercialization of biodiesel. Mixed research methods were applied to estimate ad hoc financial analysis for this case study.

The intention to provide this list of topics from the 3rd GIN Conference in Mexico City was to inform the reader on the variety of issues associated with the theme of "Private-public strategies for sustainable regional development". The seven papers described above, draw near to the challenges of the research questions driving this conference. Different ways of addressing such issues were analysed, and these included: studies at several geographical levels; multi-national company operating in diverse regional settings; multi-sectorial management in a region; cluster of companies based in a delimited region; among others. Therefore, the reader can take away from this that this special issue edition was rewarding in terms of the challenges faced through both phases: the selection and revisions of the papers. It must also be said that due to the variation of approaches to the conference theme, it was not enough evidence to draw some structured conclusions. Although, we choose to highlight that this collection of papers can be seen as proof that researchers consistently consider that "collaboration" among stakeholders is a relevant condition to implement "Private-public strategies for sustainable regional development".

Finally, we would like to send our appreciation to those who participated in the revision processes of this special issue.

\title{
Acknowledgements
}

The authors' gratitude and recognition to the organisers of the 3rd GIN Conference in Mexico City, in particular to those who with their high commitment and enthusiasm enabled it to take place: MSc Isabel Kreiner, MSc Paulina Collazo ("Instituto Tecnológico y de Estudios Superiores de Monterrey", Mexico State campus) and Dr Theo de Bruijn (Saxion, University for Applied Sciences, NL).

\author{
María-Laura Franco-García, Juan-Luis Sherwell and Aard Groen \\ Guest Editors
}

